\title{
Surgical stabilization of flail chest after trauma: when, why and how to do it?
}

\author{
Debora Brascia ${ }^{1}$, Giulia De Iaco ${ }^{1}$, Angela De Palma ${ }^{1}$, Michele Costantino ${ }^{1}$, Marcella Genualdo ${ }^{1}$, \\ Rosatea Quercia ${ }^{1}$, Angela Fiorella ${ }^{1}$, Giulia Nex ${ }^{1}$, Marcella Schiavone ${ }^{1}$, Francesca Signore ${ }^{1}$, \\ Teodora Panza ${ }^{1}$, Federico Rea ${ }^{2}$, Giuseppe Marulli ${ }^{1}$
}

\begin{abstract}
${ }^{1}$ Thoracic Surgery Unit, Department of Emergency and Organ Transplantation (DETO), University Hospital of Bari, Bari, Italy; ${ }^{2}$ Thoracic Surgery Unit, Department of Cardiologic, Thoracic and Vascular Sciences, University of Padova, Padova, Italy

Contributions: (I) Conception and design: G Marulli, D Brascia; (II) Administrative support: All authors; (III) Provision of study materials or patients: All authors; (IV) Collection and assembly of data: All authors; (V) Data analysis and interpretation: All authors; (VI) Manuscript writing: All authors; (VII) Final approval of manuscript: All authors.

Correspondence to: Prof. Giuseppe Marulli, MD, PhD. Thoracic Surgery Unit, University Hospital of Bari, G. Cesare Square 11, 70124 Bari, Italy. Email: giuseppe.marulli@uniba.it.
\end{abstract}

\begin{abstract}
Chest trauma is the third most common injury in trauma patients. In up to $15 \%$ of cases, flail chest (FC) may occur as a consequence of blunt trauma, being defined as three or more adjacent ribs fractured in at least two places. This creates a chest wall segment that moves paradoxically from the chest wall, causing both a fast evolution to respiratory failure and late complications like pneumonia, acute respiratory distress syndrome (ARDS), atelectasis, chronic pain and deformity. Non-operative management, as defined by mechanical ventilation associated with adequate pain control, has always been considered the gold standard for FC treatment; surgical fixation for FC, instead, has been routinely performed only in the last years, taking advantage of the simultaneous increase in surgeons' expertise, new technical improvements of rib-specific fixation systems and publication of encouraging randomized trials. However, the difficulty to select, stratify and compare patients in the setting of multi-systemic traumas makes extremely hard to collect data on the correct management of FC so that no precise guidelines about indications, timing and best technical surgical procedure are currently available and widely accepted. The role of early surgical intervention for FC, which is associated with better post-operative outcomes, has been widely discussed in previous studies; its main advantage, in fact, is to avoid the development of associated hypoventilation and subsequent pneumonia, hypoxemia and pulmonary fibrosis. Moreover, different surgical techniques have been described for fixation of rib fractures, but no consensus has yet been achieved on which of them could be the best procedure, being the choice mostly related to the surgeons' preferences. The use of metal plates with cortical locking screws is the most preferred choice today, also due to new technical achievement in this field.
\end{abstract}

Keywords: Flail chest (FC); trauma; surgery; chest stabilization; ribs

Received: 03 January 2019. Accepted: 10 February 2020; Published: 25 August 2020.

doi: $10.21037 /$ ccts.2020.02.10

View this article at: http://dx.doi.org/10.21037/ccts.2020.02.10

\section{Introduction}

Chest trauma is the third most common injury in trauma patients and its presence in the setting of multi-systemic trauma can significantly increase patients' morbidity and mortality. In up to $15 \%$ of cases, flail chest (FC) may occur as a consequence of blunt trauma; it is defined as a pathologic condition that happens "when three or more adjacent ribs are fractured in at least two places, creating a chest wall segment that moves paradoxically from the chest wall" $(1,2)$ (Figure 1). The fast evolution to respiratory failure and death (occurring from 10 to $36 \%$ of cases), as well as late complications like pneumonia, acute respiratory distress 

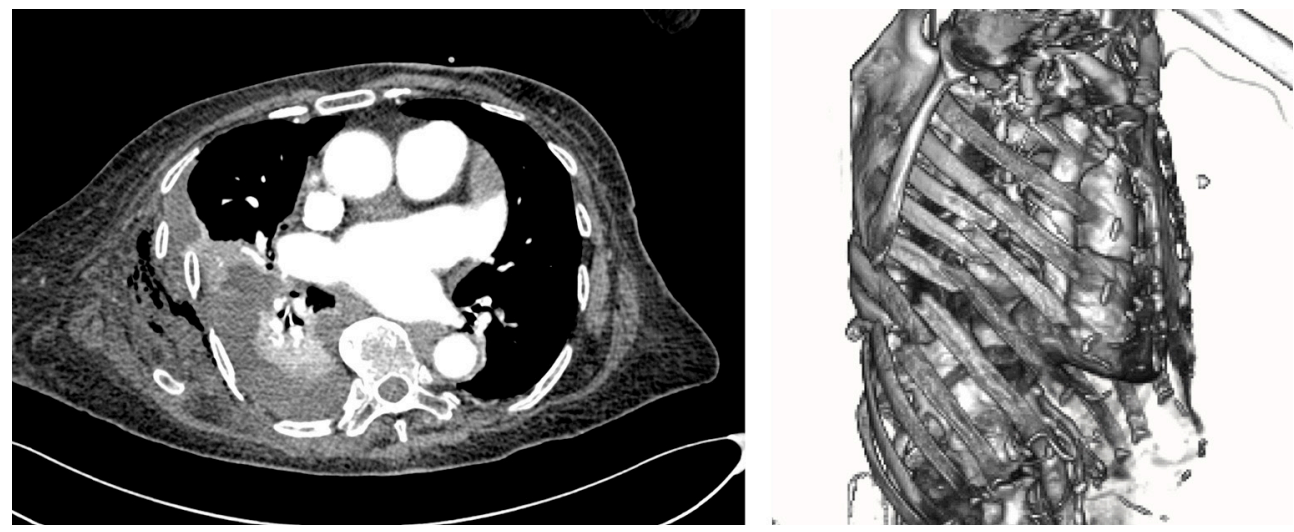

Figure 1 Chest CT-scan (3D reconstruction) showing multiple rib fractures in several sites leading to FC. FC, flail chest.

syndrome (ARDS), atelectasis, chronic pain and deformity $(3,4)$, make the proper management of $\mathrm{FC}$ a sensitive issue on which no consensus has been achieved yet. In the last years, non-operative management as defined by mechanical ventilation associated with adequate pain control, has been considered the gold standard for FC treatment. However, this management leads to longer hospital and intensive care unit stays, high morbidity and long postoperative recovery $(5,6)$. Surgical fixation for FC, thus being known from 1940s, has been routinely performed only in the last years, taking advantage of the simultaneous increase in surgeons' expertise, new technical improvements of rib-specific fixation systems and publication of encouraging randomized trials $(7,8)$. However, the difficulty to select, stratify and compare patients in the setting of multi-systemic traumas makes extremely hard to collect data on FC alone and to achieve affordable results which are not affected by the coexistent injuries.

\section{When: indications and timing}

Indication and timing of surgical stabilization of FC after trauma remain the unsolved enigmas of trauma surgery since no consensus has been achieved on them, yet.

Indications vary widely among trauma centres all over the world, depending on the single centre experience, the surgeons' expertise, the patients' global assessment, especially in polytrauma; moreover, existent Literature is lacking and greatly heterogeneous also because of the exiguity of patients enrolled in the few existing studies.

Current opinion is to proceed with surgical stabilization when respiratory failure, intractable pain and subsequent dyspnoea appear or when failure to wean from invasive ventilation occurs (9-11). Mayberry et al. (12) in a specific survey found that $\mathrm{FC}$ with failure to wean from ventilator after 7 and 14 days achieved $34 \%$ and 29\% concordance as indications for surgery, while only $8 \%$ of surgeons would indicate surgical stabilization in presence of a FC not requiring mechanical ventilation. More frequently, surgeons found their decisions on clinical evaluation alone, so that the presence of a clinical $\mathrm{FC}$ with its consequent paradoxical breathing or the presence of a severe thorax deformity alone are valid indications to proceed with surgical fixation (13). When a thoracotomy is needed because of the co-existence of a traumatic pneumothorax, pulmonary laceration (Figure 2), hemothorax (Figure 3) or diaphragmatic lesion, surgical stabilization of rib fractures should be taken into account. When pulmonary contusions associate with FC (Figure 4), there is no proof that surgical treatment is superior than the conservative one. Voggenreiter et al. (14), in fact, found that in patients with severe pulmonary contusions and fail chest, surgical fixation alone was not enough to support ventilation and when comparing patients treated with surgical fixation or not, no statistical difference was seen in terms of duration of mechanical ventilation (DMV).

Early surgical intervention, as defined as being within 24-72 hours after the trauma, should be performed, assuming other potentially life-threatening injuries have been treated (15-18). This has importance to avoid the development of associated hypoventilation and subsequent pneumonia, hypoxemia and pulmonary fibrosis. Moreover, early treatment has been proved to be associated with better post-operative outcomes. Pieracci et al. (19) in their review, in fact, divided their 551 patients who underwent surgical stabilization of rib fractures in three groups, on the 

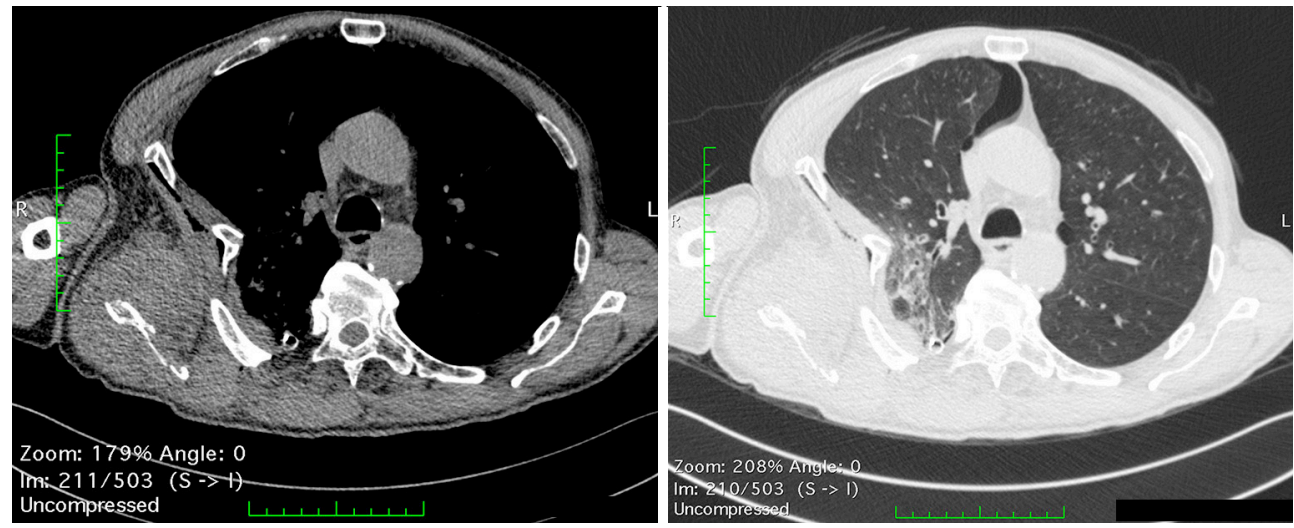

Figure 2 Chest CT-scan of a patient with chest trauma and ribs fractures with free edges inside the lung determining pulmonary laceration.
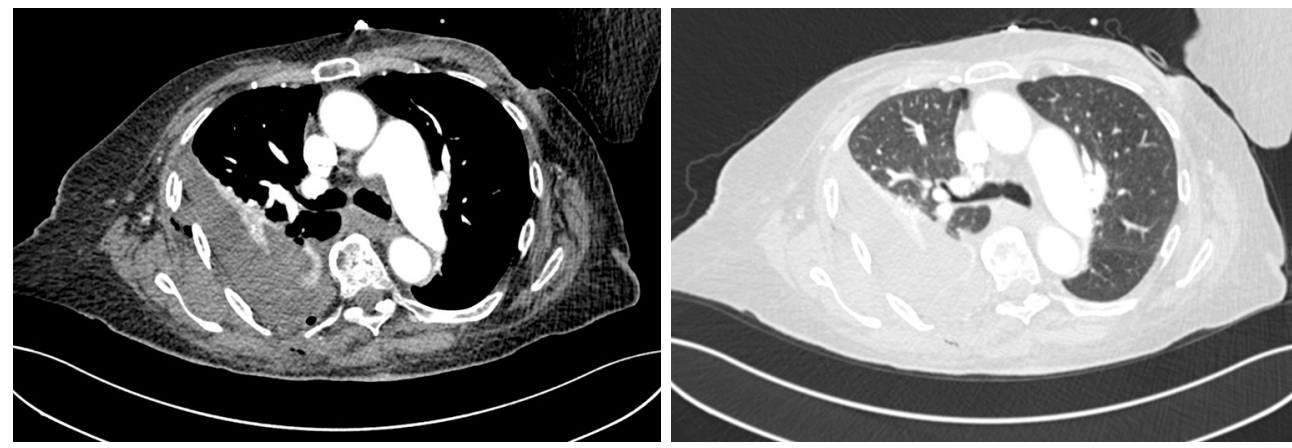

Figure 3 Chest CT-scan of a trauma patient showing hemothorax complicating ribs fractures.

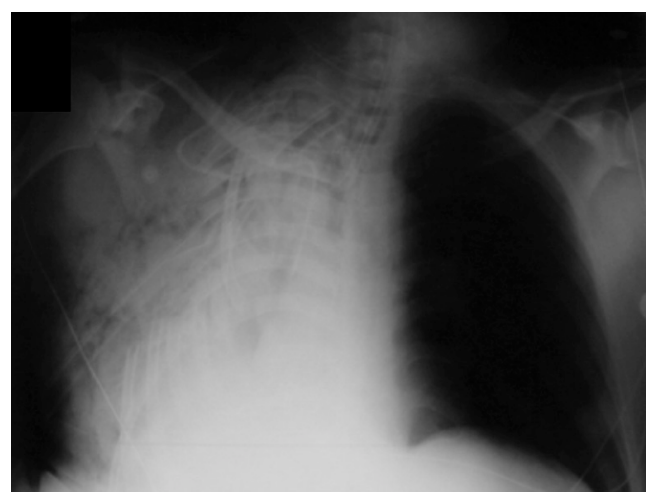

Figure 4 Chest X-ray of a patient with multiple rib fractures on the right hemithorax complicated by a massive pulmonary contusion with atelectasis and ipsilateral attraction of the mediastinum.

basis of the time of their intervention: early (day 0 ), mid (days 1-2), and late (days 3-10). They proved that patients in the late group had 2.37 times the incidence of pneumonia, 3.24 times the need for prolonged mechanical ventilation and a $26 \%$ increase likelihood of tracheostomy as compared to the early group. Furthermore, Iqbal et al. (20) in their work proved that surgery within the first 48 hours resulted in a shorter stay in the intensive care unit, shorter invasive ventilatory period, decreased risk of pneumonia and shorter overall hospital stay. Additionally, when performing late surgical stabilization, longer surgical times are required because of the inflammation; delaying stabilization for 24 to 96 hours, in fact, induces 10 to 40 times more cartilage in the fracture calluses compared with fractures immediately stabilized.

Late surgical stabilization can be performed when posttraumatic sequelae occur. Pseudoarthrosis, for example, develops when, after six months from the trauma, the physiological mechanisms of bones healing fail, leading to chronic non-union and intractable chronic pain (Figures 5,6). After this period, in fact, there are no more possibilities for the fractures to regularly heal. Failure of these mechanisms are due in $20 \%$ of cases to biological reasons which delay the callus formation (previous irradiation of the area, use 

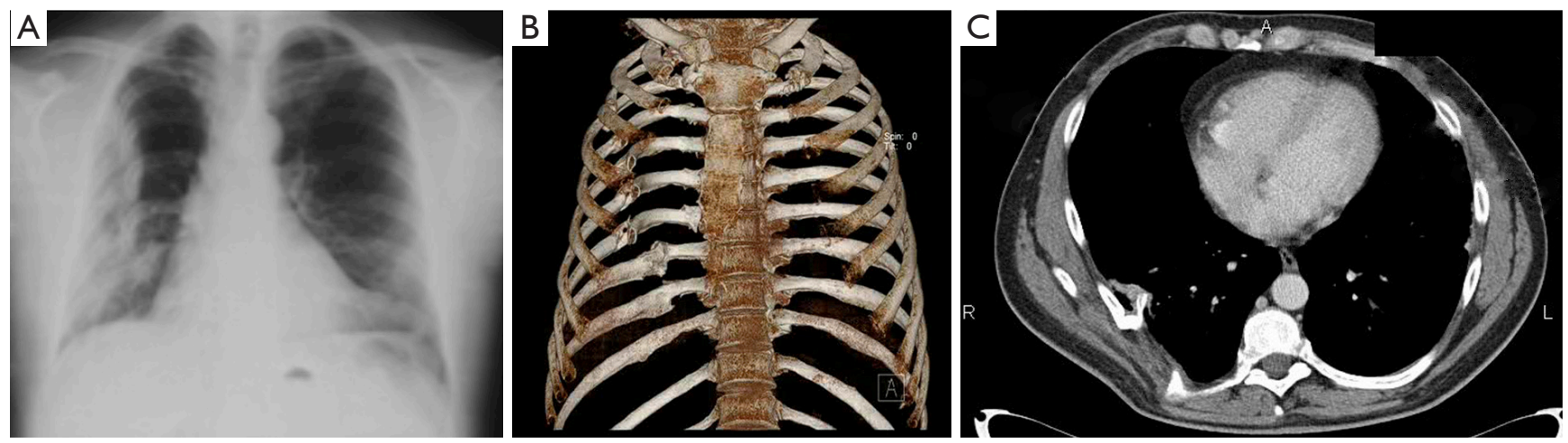

Figure 5 Six-month outcomes of non-surgical treatment in a thoracic trauma with multiple ribs fractures on the right chest determining pseudoarthrosis, chronic pain and a restrictive ventilatory syndrome. (A) Chest X-ray; (B) chest CT-scan (3D bone reconstruction); (C) CT scan.
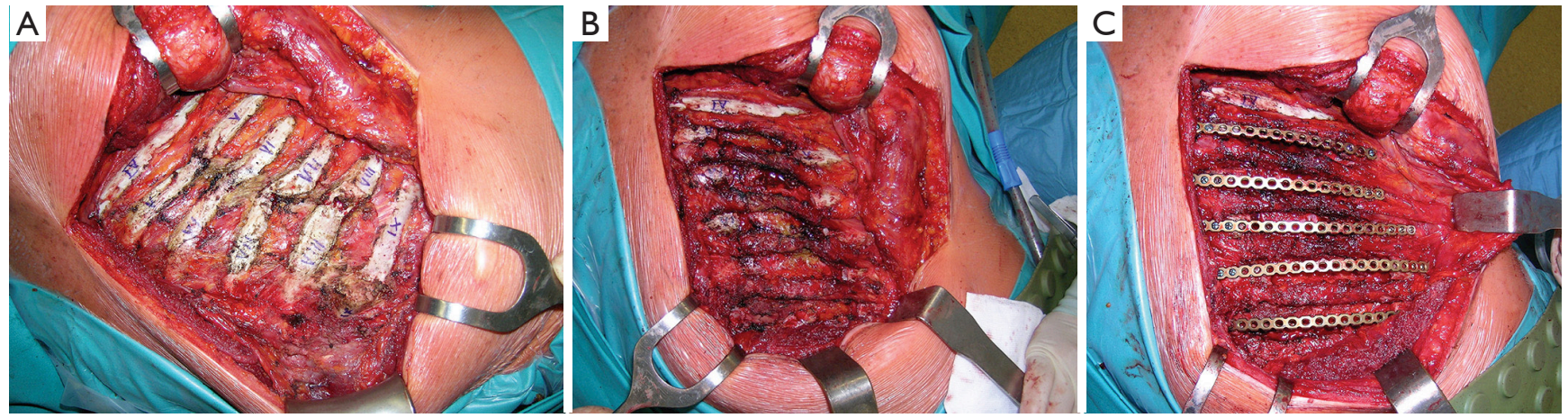

Figure 6 Intraoperative view of the wrong spontaneous healing from 4th to 9th right ribs (A), the subsequent resection (B) and replacement with titanium plates $(\mathrm{C})$.

of antimycotics, hormonal and nutritional factors such as smoking, alcohol, use of steroids) and in $80 \%$ of cases they are iatrogenic (intraoperative deperiostation, inadequate stability at the fusion site, infection of the site, accidental devascularisation and denervation).

\section{Why: pathophysiology and outcomes of surgery}

The correct management of a FC is important because of its potential evolution to respiratory failure. The FC, in fact, disrupting the continuity of the thoracic wall, moves autonomously and paradoxically because of the change of intrapleural pressures during inspiration and expiration, resulting in a variable degree of derangement of ventilation and gas exchange. Moreover, the presence of a flail segment can severely impair the ability of the ipsilateral hemithorax to expand and more oxygen is required to maintain this inefficient ventilation (21). These alterations increase the work of breathing and lead to hypoventilation and hypercapnia. Respiratory failure may occur acutely or after a variable period of time. Mortality has been described with an incidence ranging from $10 \%$ to $36 \%$ (3). Other complications due to FC are pneumonia, ARDS, pneumothorax, hemothorax, pulmonary contusion, chronic pain and chest wall deformity and atelectasis $(1,4,22)$. Zehr et al. (23) proposed a risk score for predicting mortality in FC; they found that the initial assessment of patients with FC could be done by using five risk factors: age, Glasgow Coma Score, ventilation, cardiopulmonary resuscitation and number of comorbidities. They proved that less than 6 points is consistent with $1 \%$ observed mortality, 6 to 10 points predicts $5 \%$ mortality, 11 to 15 points predicts $22 \%$ mortality, and 16 or more points predicts $46 \%$ mortality; only patients at low to medium risk of mortality should be 
candidates for operative repair.

The interest towards surgical FC stabilization has increased together with the increasing amount of randomized clinical trials proving the potential advantages of this therapeutic approach in terms of morbidity, mortality and costs $(10,24,25)$. Tanaka et al. (26), Granetzny et al. (27) and Marasco et al. (28) have performed randomized clinical trials on patients undergoing surgical stabilization for FC compared to those treated conservatively, proving a decrease in DMV and intensive care unit length of stay (ILOS), rate of pneumonia, likelihood for tracheostomy, FVC and total medical expenses (with total savings ranging from 10.000 to 14.443 dollars). A review by Slobogean et al. (25), found also a decrease in incidence of sepsis, chest pain, dyspnoea and chest deformity in favour of surgical treatment. Reducing the morbidity, pain and re-establishing the architecture of the chest allow the patients to breath normally, which means early mobilization and rehabilitation, reduction of pain medication, avoidance of long-term disability and thus, faster return to work and better quality of life $(29,30)$. Beks et al. (29), in fact, when collecting data on their cohort of patients undergoing surgical stabilization for fail chest, found that the median quality of life (QoL) as measured with the EQ-5D index at 12 months or more follow-up was 0.85. Caragounis et al. (31) also collected data about followup at 3-, 6-month and 1 year after surgical stabilization for FC. They found that patients' QoL, measured with EQ-5D index, showed median values that progressively increased from 0.78 at 6 weeks to 0.93 after 1 year, with the greatest improvement occurring between 6 weeks and 3 months after surgery. On the other hand, it was registered a decrease in patients' complaint about limited mobility and self-care, performance of usual activities and pain or discomfort from 6 weeks to 1 year after surgery.

Few studies have reported on the outcomes and rates of complications after surgery; Granetzny et al. (27), for example, reported a complication rate of $35 \%$ including mortality, pneumonia, mediastinitis, empyema, and chest wall deformity; Beks et al. (29) reported a postoperative complication rate of $59 \%$ varying from minor complications such as excess pleural fluid to major complications such as ARDS, postoperative bleeding, pneumonia, implant infection, pneumothorax and hemothorax.

\section{How: technical overview and how we do it}

Different techniques have been described in the last years for surgical fixation of rib fractures and their number increased with the increasing availability of new systems and devices. No consensus has yet been achieved on the ideal rib fractures fixation device (32), being the choice of the surgical procedure mostly related to the surgeons' expertise and technological improvements. Mayberry et al. (12) published a survey in 2009 addressing to trauma, orthopaedic trauma and thoracic surgeons, about operative intervention in patients with chest wall fractures. As a result, only $33 \%$ of trauma surgeons, $48 \%$ of orthopaedic trauma surgeons and $91 \%$ of thoracic surgeons felt competent to perform surgical stabilization in case of FC or multiple rib fractures. Overall, all the available procedures can be divided in those requiring plates and those based on intramedullary fixation.

A great number of fixation plates are currently available, varying from Judet $(14,25,33)$ or Adkins struts $(34,35)$, U-plates (36), absorbable plates to the most commonly used metal locked plates (37). Most ancient plates were applied with sutures and circled wires, while contemporary ones are applied with screws that securely lock into the plate, preventing distraction of the fracture line (38). The Judet plate is a metal plate with crimps on the side that clamps around the rib without the need for transfixing screws; the problem of this technique is the potential damage of the intercostal neurovascular bundle, causing chronic pain. For this reason, they have been replaced by the U-plates, which, being applied along the superior border of the rib, are fixed with locking screws. Absorbable plates, instead, are made of absorbable polymers which are fixed with absorbable suture material; they've been largely abandoned because of their great risk for tissue and foreign-body reactions and cyst formation in the site of implantation (39). The use of metal plates with cortical locking screws is the standard choice today also due to new technical achievement in this field. In the last years, in fact, straight traditional metallic plates have been replaced by anatomic rib plates which, due to their anatomic twist and curvature, may not only reduce the time and complexity of the operative procedure but also contribute to durable fixation by eliminating the need for templating and pre-bending of the plate (37). Moreover, the locking plate has a corresponding threaded plate hole so that the locking head screws can be engaged in the plate; this avoid the development of high pressures of plate on the bone and reduces interference to the blood supply to the bone underlying the plate, while providing adequate rigidity and stability. Besides, when considering FC stabilization, long anatomic rib plates enable bridging and suspension of the flail segment, but they also can be shortened and 

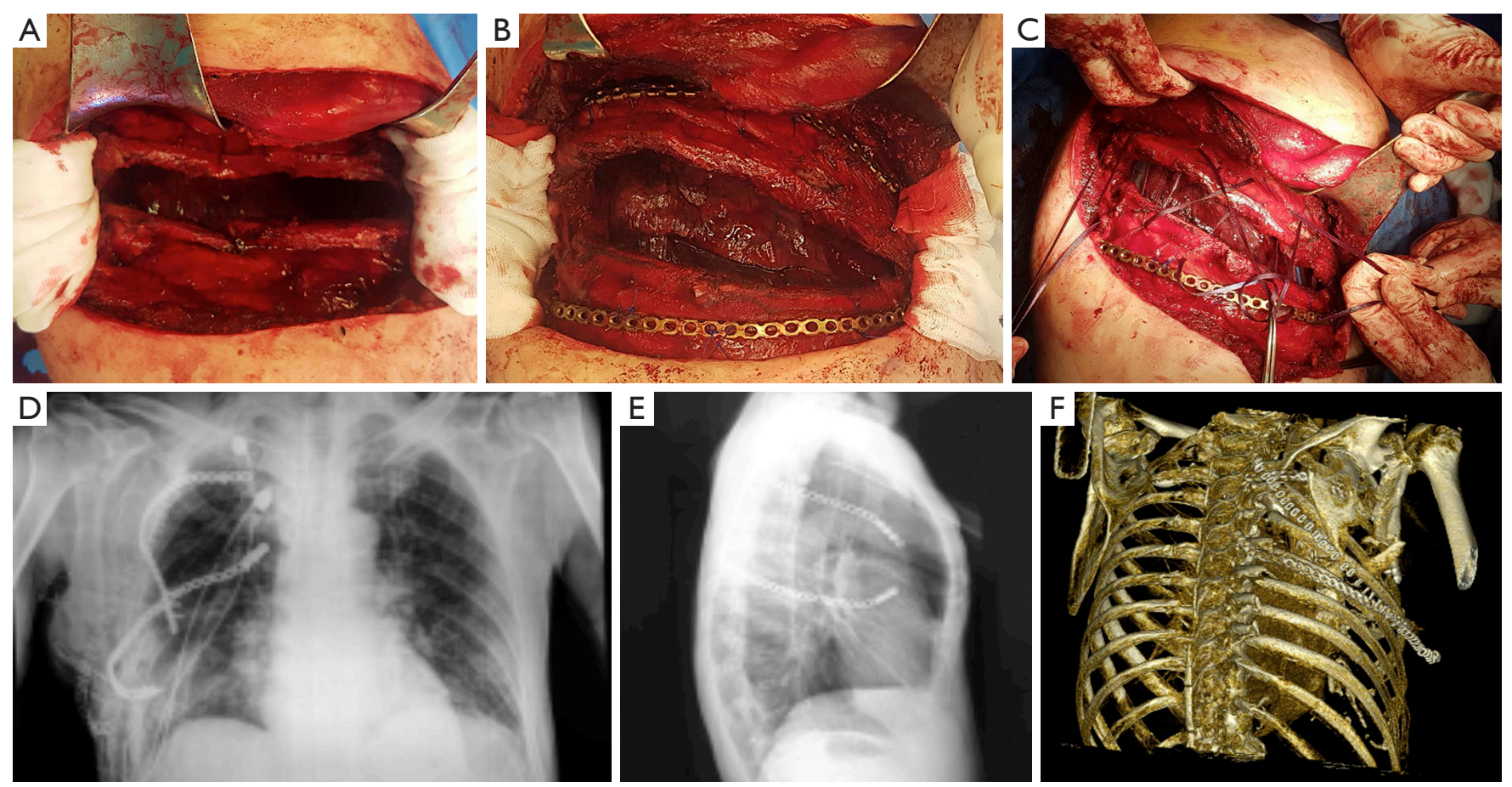

Figure 7 Intraoperative view of surgical field after a postero-lateral thoracotomy (A); two long titanium plates are placed to stabilize the chest wall (B,C). Postoperative chest X-ray in antero-posterior (D) and lateral (E) projections, and 3D bone reconstruction (F) show the final result.

shaped with dedicated devices (bending pliers, shortcuts) for fixation of single rib or sternal fractures (Figure 7); in fact, in order to reproduce the physiological flexibility of ribs, plates are made of elastic titanium and they are over three times less stiff than titanium sternal locking plates and over five times less stiff than stainless steel $3.5 \mathrm{~mm}$ reconstruction plates (40).

Intramedullary fixation ranges over various techniques; in the last 40 years, Kirschner wires have been widely used, especially when approaching hardly accessible posterior fractures; the wires enable intramedullary pinning of ribs, while perhaps not achieving the result of fracture fixation, often leading to dislodgement and migration. Intramedullary splints, instead, require smaller incisions so that they too can be used for posterior and subscapular rib fractures. New intramedullary splints have a rectangular profile to assure rotational stability within the canal, and a locking feature to limit migration and rotation of the implant; moreover, only one screw is needed to secure each splint.

Surgical approach has to be chosen on the basis of fractures' location, to guarantee adequate exposure and wide surgical field, while preserving as much as muscles as possible and good aesthetic results. Anterior FC has to be accessed with the patient in a supine position, performing an incision along the inframammary fold which can be expanded to a bilateral inframammary incision when a contemporary sternal access is needed. FC often involve a combination of anterior, lateral and posterior fractures, so that the most useful access is the traditional posterolateral thoracotomy with the patient in a lateral decubitus position. Attention must be paid to access the costal layer by creating a sub-cutaneous flap and trying to avoid any muscle division to preserve as much respiratory function as possible. Rib fractures should be localized and cleared from soft-tissue attachments; the periosteum, instead, should be preserved because it allows bone regeneration. It is important to obtain a minimum of $2.5 \mathrm{~cm}$ per side of healthy and clear rib, since a minimum of three screws on each side of the fracture are needed to properly secure the plate. At this point, the surgeon is able to reduce and consequently approximate broken rib segments by using ratchet locks and reduction forceps and to start surgical fixation using the MatrixRIB system (DePuy Synthes ${ }^{\circledR}$ CMF, Switzerland). 
It is useful to assess rib thickness by inserting a calliper tip through a small incision in the superior border of the rib, in the intercostal space; this thickness will allow the surgeon to choose the right screws and to drill the holes at the right depth, avoiding complications such as pneumothorax or hemothorax due to lesions of the lungs. Then, a template can be used, to properly assess the correct length, twist and curvature of the rib; when managing a $\mathrm{FC}$, evidences are in favour of stabilizing both fracture lines involved in the flail segment, since it is useful to prevent long-term deformities and dislodgements (41). To match the template, the plate can be shaped by using the bending pliers and cut to the desired length by using the shortcut and then positioned on the fractured rib. Once the perfect match has been achieved, holding forceps hold the plate on the rib; then drill guide can be used to align the drill hole with the plate hole and, once selected the drill stop as determined by the measure of rib thickness, the holes are drilled. Proper locking screws, considering the rib thickness, are chosen and placed bicortically, minimum three on each side. Once finished the fixation procedure, closure should be performed respecting the anatomic layers. A chest drain should be placed in the suspicion of pre or postoperative pneumothorax, hemothorax or large pleural effusion. Positioning of a closed suction drain in the sub-cutaneous space depends on host factors and surgeon's will.

\section{Conclusions}

FC management is still largely relied on personal surgeons' experience, due to the absence of a shared consensus about timing, indications and best surgical treatment. The currently poor availability of data in Literature is due to the difficulty to enroll patients in the setting of multi-trauma injuries; FC, in fact, is not so common and almost always occurs in association with pulmonary and extra-pulmonary damages. Most of the published studies, in fact, takes into account both patients with FC and ribs fractures, thus being the first strictly related to highest morbidity and mortality rates.

Current evidences are in favour of surgical fixation of FCs, having this procedure been proved to decrease DMV and intensive care unit length of stay, rate of pneumonia, likelihood for tracheostomy, FVC and total medical expenses while increasing short and long-term quality of life.

\section{Acknowledgments}

Funding: None.

\section{Footnote}

Provenance and Peer Review: This article was commissioned by the Guest Editors (Francesco Zaraca, Reinhold Perkmann, Luca Bertolaccini and Roberto Crisci) for the series "Thoracic Surgery Without Borders" published in Current Challenges in Thoracic Surgery. The article has undergone external peer review.

Conflicts of Interest: All authors have completed the ICMJE uniform disclosure form (available at https://ccts. amegroups.com/article/view/10.21037/ccts.2020.02.10/ coif). The series "Thoracic Surgery Without Borders" was commissioned by the editorial office without any funding or sponsorship. GM serves as an unpaid editorial board member of Current Challenges in Thoracic Surgery from January 2020 to December 2021. The authors have no other conflicts of interest to declare.

Ethical Statement: The authors are accountable for all aspects of the work in ensuring that questions related to the accuracy or integrity of any part of the work are appropriately investigated and resolved.

Open Access Statement: This is an Open Access article distributed in accordance with the Creative Commons Attribution-NonCommercial-NoDerivs 4.0 International License (CC BY-NC-ND 4.0), which permits the noncommercial replication and distribution of the article with the strict proviso that no changes or edits are made and the original work is properly cited (including links to both the formal publication through the relevant DOI and the license). See: https://creativecommons.org/licenses/by-nc-nd/4.0/.

\section{References}

1. Ciraulo DL, Elliott D, Mitchell KA, et al. Flail chest as a marker for significant injuries. J Am Coll Surg 1994;178:466-70.

2. Xu JQ, Qiu PL, Yu RG et al. Better short-term efficacy of treating severe flail chest with internal fixation surgery compared with conservative treatments. Eur J Med Res 2015;20:55.

3. Ranasinghe AM, Hyde JA, Graham TR. Management of flail chest. Trauma 2001;3:235-47.

4. Dehghan N, de Mestral C, McKee MD, et al. Flail chest injuries: a review of outcomes and treatment practices from the National Trauma Data Bank. J Trauma Acute 
Care Surg 2014;76:462-68.

5. Doben AR, Eriksson EA, Denlinger CE, et al. Surgical rib fixation for flail chest deformity improves liberation from mechanical ventilation. J Crit Care 2014;29:139-43.

6. Vana PG, Neubauer DC, Luchette FA. Contemporary management of flail chest. Am Surg 2014;80:527-35.

7. Bemelman M, Poeze M, Blokhuis TJ, et al. Historic overview of treatment techniques for rib fractures and flail chest. Eur J Trauma Emerg Surg 2010;36:407-15.

8. Kasotakis G, Hasenboehler EA, Streib EW, et al. Operative fixation of rib fractures after blunt trauma: a practice management guideline from the Eastern Association for the Surgery of Trauma. J Trauma Acute Care Surg 2017;82:618-26.

9. Velasquez M, Ordoez CA, Parra MW, et al. Operative versus Nonoperative Management of Multiple Rib Fractures. Am Surg 2016;82:e103-05.

10. Bhatnagar A, Mayberry J, Nirula R. Rib fracture fixation for flail chest: what is the benefit? J Am Coll Surg 2012;215:201-5.

11. Ingoe HMA, Coleman E, Eardley W, et al. Systematic review of systematic reviews for effectiveness of internal fixation for flail chest and rib fractures in adults. BMJ Open 2019;9:e023444.

12. Mayberry JC, Ham LB, Schipper PH, et al. Surveyed opinion of American trauma, orthopedic, and thoracic surgeons on rib and sternal fracture repair. J Trauma 2009;66:875-79.

13. Beks RB, de Jong MB, Sweet A, et al. Multicentre prospective cohort study of nonoperative versus operative treatment for flail chest and multiple rib fractures after blunt thoracic trauma: study protocol. BMJ Open 2019;9:e023660.

14. Voggenreiter G, Neudeck F, Aufmkolk M, et al. Operative chest wall stabilization in flail chest. Outcomes of patients with or without pulmonary contusion. J Am Coll Surg 1998;187:130-8.

15. Pieracci FM, Rodil M, Stovall RT, et al. Surgical stabilization of severe rib fractures. J Trauma Acute Care Surg 2015;78:883-87.

16. Nirula R, Diaz Jr. JJ, Trunkey DD, et al. Rib fracture repair: indications, technical issues, and future directions. World J Surg 2009;33:14-22.

17. Hasenboehler EA, Bernard AC, Bottiggi AJ, et al. Treatment of traumatic flail chest with muscular sparing open reduction and internal fixation: description of a surgical technique. J Trauma 2011;71:494-501.

18. Sarani B, Schulte L, Diaz JJ. Pitfalls associated with open reduction and internal fixation of fractured ribs. Injury 2015;46:2335-40.

19. Pieracci FM, Coleman J, Ali-Osman F, et al. A multicenter evaluation of the optimal timing of surgical stabilization of rib fractures. J Trauma Acute Care Surg 2018;84:1-10.

20. Iqbal HJ, Alsousou J, Shah S, et al. Early Surgical Stabilization of Complex Chest Wall Injuries Improves Short-Term Patient Outcomes. J Bone Joint Surg Am 2018;100:1298-308.

21. Davignon K, Kwo J, Bigatello LM. Pathophysiology and management of the flail chest. Minerva anestesiol 2004;70:193-99.

22. Clark GC, Schecter WP, Trunkey DD. Variables affecting outcome in blunt chest trauma: flail chest vs. pulmonary contusion. J Trauma 1988;28:298-304.

23. Zehr M, Klar N, Malthaner RA. Risk Score for Predicting Mortality in Flail Chest. Ann Thorac Surg 2015;100:223-28.

24. Leinicke JA, Elmore L, Freeman BD, et al. Operative management of rib fractures in the setting of flail chest: a systematic review and meta-analysis. Ann Surg 2013;258:914-21.

25. Slobogean GP, MacPherson CA, Sun T, et al. Surgical fixation vs nonoperative management of flail chest: a metaanalysis. J Am Coll Surg 2013;216:302-11.e1.

26. Tanaka H, Yukioka T, Yamaguti Y, et al. Surgical stabilization of internal pneumatic stabilization? A prospective randomized study of management of severe flail chest patients. J Trauma 2002;52:727-32.

27. Granetzny A, Abd El-Aal M, Emam E, et al. Surgical versus conservative treatment of flail chest. Evaluation of the pulmonary status. Interact Cardiovasc Thorac Surg 2005;4:583-87.

28. Marasco SF, Davies AR, Cooper J, et al. Prospective randomized controlled trial of operative rib fixation in traumatic flail chest. J Am Coll Surg 2013;216:924-32.

29. Beks RB, de Jong MB, Houwert RM, et al. Long-term follow-up after rib fixation for flail chest and multiple rib fractures. Eur J Trauma Emerg Surg 2019;45:645-54.

30. Qiu M, Shi Z, Xiao J, et al. Potential Benefits of Rib Fracture Fixation in Patients with Flail Chest and Multiple Non-flail Rib Fractures. Indian J Surg 2016;78:458-63.

31. Caragounis EC, Fagevik OM, Pazooki D, et al. Surgical treatment of multiple rib fractures and flail chest in trauma: a one-year follow-up study. World J Emerg Surg 2016;11:27. 
32. Simon B, Ebert J, Bokhari F, et al. Management of pulmonary contusion and flail chest: an Eastern Association for the Surgery of Trauma practice management guideline. J Trauma Acute Care Surg 2012;73:S351-61.

33. Judet R. Osteosynthese costale. Rev Chir Orthop 1973;59:334-5.

34. Adkins PC, Groff DB, Blades B. Experiences with metal struts for chest wall stabilization. Ann Thorac Surg 1968;5:246-54.

35. Nirula R, Allen B, Layman R, et al. Rib fracture stabilization in patients sustaining blunt chest injury. Am Surg 2006;72:307-9.

36. Sales JR, Ellis TJ, Gillard J, et al. Biomechanical testing of a novel, minimally invasive rib fracture plating system. J Trauma 2008;64:1270-4.

37. Bottlang M, Helzel I, Long WB, et al. Anatomically

doi: $10.21037 /$ ccts.2020.02.10

Cite this article as: Brascia D, De Iaco G, De Palma A, Costantino M, Genualdo M, Quercia R, Fiorella A, Nex G, Schiavone M, Signore F, Panza T, Rea F, Marulli G. Surgical stabilization of flail chest after trauma: when, why and how to do it? Curr Chall Thorac Surg 2020;2:28. contoured plates for fixation of rib fractures. J Trauma 2010;68:611-5.

38. Fitzpatrick DC, Denard PJ, Phelan D, et al. Operative stabilization of flail chest injuries: review of literature and fixation options. Eur J Trauma Emerg Surg 2010;36:427-33.

39. Vu KC, Skourtis ME, Gong X, et al. Reduction of rib fractures with a bioresorbable plating system: preliminary observations. J Trauma 2008;64:1264-69.

40. Bottlang M, Walleser S, Noll M, et al. Biomechanical rationale and evaluation of an implant system for rib fracture fixation. Eur J Trauma Emerg Surg 2010;36:417-26.

41. Marasco S, Liew S, Edwards E, et al. Analysis of bone healing in flail chest injury: do we need to fix both fractures per rib? J Trauma Acute Care Surg 2014;77:452-58. 